\title{
Learning of Biochemistry and Cell Biology: Case Study of the School of Physiotherapy from ONCE
}

Gonçalves, N. T. L. P. ; Kauark, F. S. ${ }^{1,2}$; Comarú, M. W. ${ }^{1,2}$

${ }^{1}$ Programa de Pós-Graduação em Educação em Ciências e Matemática, Instituto Federal do Espírito Santo, IFES, campus Vitória, ES, Brazil; ' Instituto Federal do Espírito Santo, IFES, campus Vila Velha, ES, Brazil.

Introduction: Teaching biomedical disciplines for students with disabilities in higher education is considered a major challenge, especially when it comes to the curriculum, the methods and the resources. In Brazil there are few reports on how the processes of teaching and learning biomedical disciplines in higher education are conducted. In Spain, since the 70's the School of Physiotherapy from the National Organization of Spanish blind people (ONCE) offers exclusively for students with disabilities undergraduate degree in Physiotherapy, as well as many post graduation courses in biomedicine. Thus, the aim of this study was to verify in situ what were the resources and methods used by the professors of biochemistry and cell biology to teach their students with visual impairments.

Material and Methods: Technical visits were conducted using the following instruments to collect the data: Unstructured interviews with teachers, students and staff (audio-recorded and later transcribed) and classroom observation using photographs and reports. The data generated by the interviews were analyzed by the discourse analysis.

Discussion and results: Reports indicated that the main methodological resources are: embossed boards made with Swell paper and with the help of an oven called Ricoh fuser $\circledR$; commercially sold models of cells and body structures; the technique of descriptive discourse where the professor describes an image to be studied, individual touch techniques where the professor shows an image using the touch of the student. It was observed that certain sectors inside the school are especially distinguished. Overall, the school does not present any other routine different from a regular school, and according to the professors, it happens intentionally, so that the future professionals are able to work in environments not adapted for their needs.

Conclusion: The observed adjustments in the school of physiotherapy at ONCE could be seen as an example for Brazilian institutions.

Keywords: Learning of biochemistry, disabilities

Acknowledgements: FAPES and CAPES 